\title{
The asexual morph of Trichomerium gloeosporum
}

\author{
Hongsanan $\mathbf{S}^{1,2,3}$, Tian $\mathbf{Q}^{1,2,3}$, Hyde $\mathrm{KD}^{1,2,3}$, Hu DM ${ }^{4 *}$ \\ ${ }^{1}$ Key Laboratory for Plant Diversity and Biogeography of East Asia, Kunming Institute of Botany, Chinese Academy of \\ Science, Kunming 650201, Yunnan, People's Republic of China \\ ${ }^{2}$ World Agroforestry Centre, East and Central Asia, Kunming 650201, Yunnan, People's Republic of China \\ ${ }^{3}$ Center of Excellence in Fungal Research, Chiang Rai 57100, Thailand \\ ${ }^{4}$ College of Bioscience and Bioengineering, Jiangxi Agricultural University, Nanchang 330045, People's Republic of \\ China
}

Hongsanan S, Tian Q, Hyde KD, Hu DM. 2016 - The asexual morph of Trichomerium gloeosporum. Mycosphere 7 (9), 1473-1479, Doi 10.5943/mycosphere/7/9/18

\begin{abstract}
Trichomerium species are sooty molds that develop superficially on the host surface. There is little morphological and molecular data for the genus. The asexual morphs of Trichomerium have been poorly studied, with also lack molecular data. Several researchers have noted that Tripospermum is possibly the asexual morph of Trichomerium species. In this study, we collected Trichomerium-like taxa from leaves in northern Thailand. The sexual structures found on the specimen were identified as Trichomerium gloeosporum, and Tripospermum-like conidia were also associated with the sexual morph. Cultures were obtained from single Tripospermum-like conidia and sequenced. Phylogenetic analyses generated from maximum likelihood and Bayesian analyses of combined LSU and ITS sequence data demonstrate that our strains isolated from Tripospermumlike conidia clustered with strains of T. gloeosporum with high statistical support. A description of the asexual morph of T. gloeosporum with molecular data is provided.
\end{abstract}

Key words - Asexual morph - Trichomeriaceae - sooty molds

\section{Introduction}

The genus Trichomerium was introduced by Spegazzini (1918), and had been regarded as belonging to the order Capnodiales (Dothideomycetes). Trichomerium species feed on honey dew from insect excretions (Chomnunti et al. 2012a) and are characterized by forming hyphal networks on the surface of plants, globose to subglobose ascomata, with setae surrounding the upper part of ascomata, bitunicate asci, and septate, hyaline ascospores, with or without mucilaginous sheaths (Chomnunti et al. 2012a). Trichomerium species are referred as sooty molds, and similar to species in Capnodiaceae and Chaetothyriaceae based on their black hyphal networks (Chomnunti et al. 2012a, b, 2014). However, Trichomerium differs from other species in these two families in having an apical ascal ring, ascospores with or without sheaths and in their septation (Chomnunti et al. 2012a, b, 2014). Chomnunti et al. (2012a) demonstrated that Trichomerium species clustered separately from Capnodiaceae and Chaetothyriaceae, but in Chaetothyriales (Eurotiomycetes) based on their phylogenetic tree. Therefore, Trichomerium was introduced as a new family (Chomnunti et al. 2012a). Réblová et al. (2013) accepted species of Trichomeriaceae as a part of Chaetothyriaceae. Isola et al. (2016) and Nascimento et al. (2016) also discovered that some extremotolerant fungi growing on rock surfaces were phylogenetically related to species of 
Trichomerium. Most of these species have been found on rocks, and were slow-growing (Isora et al. 2016). The taxonomic position of non-sporulating species is uncertain, however, they have been placed in Trichomeriaceae and Chaetothyriaceae based on phylogenetic analyses (Tsuneda et al. 2011, Réblová et al. 2013, Hubka et al. 2014, Isola et al. 2016). Sequence data from Arthrocladium species were provided, and they are phylogenetically related to Trichomerium (Nascimento et al. 2016). However, Nascimento et al. (2016) found that one of their Arthrocladium isolates caused a fatal disseminated infection in a human, with GATA-2 immune defect (Egenlauf et al. 2015), while two other isolates were as inhabitants of rotten wood. Thus, Nascimento et al. (2016) noted that Trichomeriaceae mainly comprises epiphytic and epilithic organisms, and the placement of the family in phylogenetic tree presently comprises species of Arthrocladium, Bradymyces, Exophiala, Knufia, and unidentified species of Chaetothyriales. The asexual morph of Trichomerium species is uncertain and several researchers did note that Trichomerium possibly had Tripospermum morphs (Chomnunti et al. 2012a, Crous et al. 2015). There was no molecular evidence to support this idea, until Crous et al. (2015) confirmed this association when introducing a new species Trichomerium dioscoreae with Tripospermum-like morphs. Their blast results showed that the new species was closely related to Trichomerium gloeosporum, but was a distinct new species (ITS, 92\%). Below we report on the asexual morph of Trichomerium gloeosporum and resolve the confusion with a phylogenetic tree.

\section{Materials \& Methods}

Morphology and isolation

Specimens of "Trichomerium"-like taxa were collected in Chiang Rai, Thailand. The morphology was observed and photographed under a stereomicroscope. Micromorphological characters were studied under a compound microscope, and photographed using a Nikon80i. Measurements were determined using Tarosoft(R) Image Frame Work v. 0.9.7. Slides were preserved in lactoglycerol. A spore suspension was obtained, and dropped onto the surface of the PDA plate. The plate was incubated 12 hour of light/12 hours dark at room temperature $\left(25-28{ }^{\circ} \mathrm{C}\right)$ and observed every 12 hours. Germinated spores were transferred onto the surface of fresh PDA (Chomnunti et al. 2014). Herbarium specimens are deposited in the Mae Fah Luang University Herbarium (MFLU), Chiang Rai, Thailand, and living cultures is deposited in both Mae Fah Luang University Culture Collection (MFLUCC). Faces of fungi numbers and Index Fungorum numbers are as explained in Jayasiri et al. (2015) and Index Fungorum (2016).

\section{Phylogenetic analyses}

Fungal isolates were grown on PDA for 7 days at $25{ }^{\circ} \mathrm{C}$. Genomic DNA was extracted from the growing mycelium using the Biospin Fungus Genomic DNA Extraction Kit-BSC14S1 (BioFlux ${ }^{\circledR}$, P.R. China); following the instructions of the manufacturer (Hangzhou, P.R. China). Polymerase chain reaction (PCR) was carried out using known primer pairs LROR/LR5 to amplify the large subunit rDNA region, and ITS1/ITS4 to amplify internal transcribed spacer region (White et al. 1990). The amplification was performed following the instructions, and were set up for initial denaturation of 5 minutes at $95{ }^{\circ} \mathrm{C}$, followed by 35 cycles of 45 seconds at $94{ }^{\circ} \mathrm{C}, 45$ seconds at 52 ${ }^{\circ} \mathrm{C}$ and 90 seconds at $72{ }^{\circ} \mathrm{C}$, final extension period of 10 minutes at $72{ }^{\circ} \mathrm{C}$. Products of PCR were checked on $1 \%$ agarose electrophoresis gels stained with ethidium bromide, and sequenced by Majorbio Co., China. DNA. Primer sequences and database are available in GenBank.

Sequence data of related strains based on BLAST results were downloaded from GenBank to supplement the dataset (Table 1). The data set was aligned with our new strains using MAFFT (Katoh et al. 2009), and checked manually using Bioedit (Hall 1999). Ceramothyrium thailandicum was selected as the outgroup taxon. Maximum likelihood analysis was performed by using raxmlGUIv.0.9b2 (Silvestro \& Michalak 2012). The search strategy was set to rapid boot strapping and the analysis was carried out using GTRGAMMA model of nucleotide substitution. Maximum likelihood bootstrap values equal or greater than $70 \%$ are given as the first set of numbers above the nodes (Fig. 1). The model of evolution was performed by using MrModeltest 2.2 (Nylander et 
al. 2008). Posterior probabilities (PP) (Rannala \& Yang 1996, Zhaxybayeva \& Gogarten 2002) were determined by Markov Chain Monte Carlo sampling (MCMC) in MrBayesv 3.1.2 software (Huelsenbeck \& Ronquist 2001). Six simultaneous Markov chains were run for 1,000,000 generations and trees were sampled every 100th generation. Thus, 10,000 trees were obtained. The first 2,000 trees were discarded based on the result from Tracer software. The remaining 8,000 trees were performed for calculating posterior probabilities (Cai et al. 2006, 2008). Bayesian posterior probabilities (BYPP) equal or greater than 0.95 are given as the second set of numbers above the nodes (Fig. 1).

Table 1: Taxa used in the phylogenetic analysis and GenBank accession numbers (LSU and ITS) and species voucher/culture numbers.

\begin{tabular}{llll}
\hline \multirow{2}{*}{ Species } & \multicolumn{2}{c}{ Voucher/culture } & \multicolumn{2}{c}{ Accession numbers } \\
\cline { 3 - 4 } & CBS 136243 & KT337444 & KTS \\
\hline Arthrocladium fulminans & CBS 127021 & KT337446 & KT337441 \\
Arthrocladium tardum & CBS 134919 & KT337447 & KT337442 \\
Arthrocladium tardum & CBS 134926 & KT337445 & KT337440 \\
Arthrocladium tropicale & CR08/2-1 & FJ538960 & FJ538960 \\
Chaetothyriales sp. & CR08/2-2 & FJ538959 & FJ538959 \\
Chaetothyriales sp. & M-Mo2 & HQ634636 & HQ634636 \\
Chaetothyriales sp. & CN-Cre-Bo3-2 & HQ634620 & HQ634620 \\
Chaetothyriales sp. & CN-Phe1-1 & HQ634622 & HQ634622 \\
Chaetothyriales sp. & CN-Cre-Bo1-4 & HQ634614 & HQ634614 \\
Chaetothyriales sp. & M-Camp4 & HQ634626 & HQ634626 \\
Chaetothyriales sp. & CBS 985.96 & KF928485 & KF928421 \\
Cladophialophora modesta & CBS 454.82 & KC809991 & EU137293 \\
Cladophialophora mycetomatis & MFLUCC10-0884 & JX313660 & NR_132965 \\
Trichomerium deniqulatum & CBS:138870 & KP004496 & KP004468 \\
Trichomerium dioscoreae & MFLUCC10-0078 & JX313661 & JX313655 \\
Trichomerium foliicola & MFLUCC10-0073 & JX313658 & JX313652 \\
Trichomerium foliicola & MFLUCC10-0058 & JX313659 & JX313653 \\
Trichomerium foliicola & MFLUCC10-0054 & JX313657 & JX313651 \\
Trichomerium foliicola & MFLUCC10-0087 & JX313662 & JX313656 \\
Trichomerium gloeosporum & MFLUCC15-0209 & KY381953 & KY381954 \\
Trichomerium gloeosporum & MFLUCC15-0208 & KY381951 & KY381952 \\
Trichomerium gloeosporum & & & \\
\hline & & &
\end{tabular}

Trichomerium gloeosporum Chomnunti \& K.D. Hyde

Facesoffungi number FoF02826

Systematic placement: Ascomycota, Pezizomycotina, Eurotiomycetes,

Chaetothyriomycetidae, Chaetothyriales, Chaetothyriaceae.

Epiphytic or saprobic on the upper surface of leaves. Superficial hyphae, branched, septate, slightly constricted at the septa, pale brown to dark brown, hyphal networks cover the surface of hosts. Sexual morph: Ascomata 100-117 high $\times 115-120 \mu \mathrm{m}$ diam. $(\bar{x}=115 \times 118 \mu \mathrm{m}, \mathrm{n}=5)$, superficial on the surface of hosts, solitary to clustered, subglobose to globose, brown to dark brown, with abundant setae. Ascomatal setae $105-122 \times 4-6 \mu \mathrm{m}(\bar{x}=120 \times 5 \mu \mathrm{m}, \mathrm{n}=20)$, septate, dark brown or olivaceous, straight, tapering toward the apex. Peridium $14-21 \mu \mathrm{m}$ wide $(\bar{x}=18 \mu \mathrm{m}$, $\mathrm{n}=10$ ), two layers, the outer layer of brown to dark brown cells of textura prismatica, inner layer of pale brown to hyaline of flattened cells. Hamathecium aparaphysate. Asci 58-62 $\times 20-24 \mu \mathrm{m}(\bar{x}$ $=60 \times 22 \mu \mathrm{m}, \mathrm{n}=10), 8$-spored, bitunicate, ellipsoidal to cylindrical, with a short pedicel, with an apical ring. Ascospores 20-22 × 5-7 $\mu \mathrm{m}(\bar{x}=21 \times 6 \mu \mathrm{m}, \mathrm{n}=20), 2$-seriate, hyaline, fusoid, 2-3septate, rounded at the ends, with a mucilaginous sheath (description of sexual morph modified from Chomnunti et al. 2012a and own observations). Asexual morph: Conidiophores reduced to 
conidiogenous cells, conidia arising directly from hyphae. Conidia solitary, hyaline to pale brown, or grayish, giving rise to 3-4 lateral arms from a central cell. Conidial arms 29-35 $\times 5-7 \mu \mathrm{m}(\bar{x}=$ $32 \times 6 \mu \mathrm{m}, \mathrm{n}=10$ ), pale brown to grayish, 2-5-septate, not constricted or slightly constricted, darker at the septa, subcylindrical, tapering to the apex, with rounded ends, smooth-walled.

Culture on PDA: Conidia germinating on PDA at $22-25{ }^{\circ} \mathrm{C}$ for $12 \mathrm{~h}$ dark/ $12 \mathrm{~h}$ light, germ tubes appearing from each branch of conidia, hyaline to bluish, but becoming dark brown to black. Colonies reaching $1 \mathrm{~cm}$ diameter after 4 days on PDA at $22-25{ }^{\circ} \mathrm{C}$, colonies superficial to erumpent, velvety surface, dark brown, reddish-brown at the margin, dark brown to grayish sparse aerial hyphae outer region. Conidia produced in PDA after 7 days incubation.

Material examined: THAILAND, Chiang Rai Province, Tasud, STK resort, on living leaves of Gardenia sp. (Rubiaceae), 21 January 2015, S. Hongsanan STK07 (MFLU 16-2885), living culture, MFLUCC 15-0208, MFLUCC 15-0209. THAILAND, Chiang Rai Province, Mae Khao Tom, on living leaves of Ficus annulata (Moraceae), February 2013, S. Hongsanan CC1 (MFLU 16-2926), living culture, MFLUCC 13-0780, MFLUCC 13-0789.

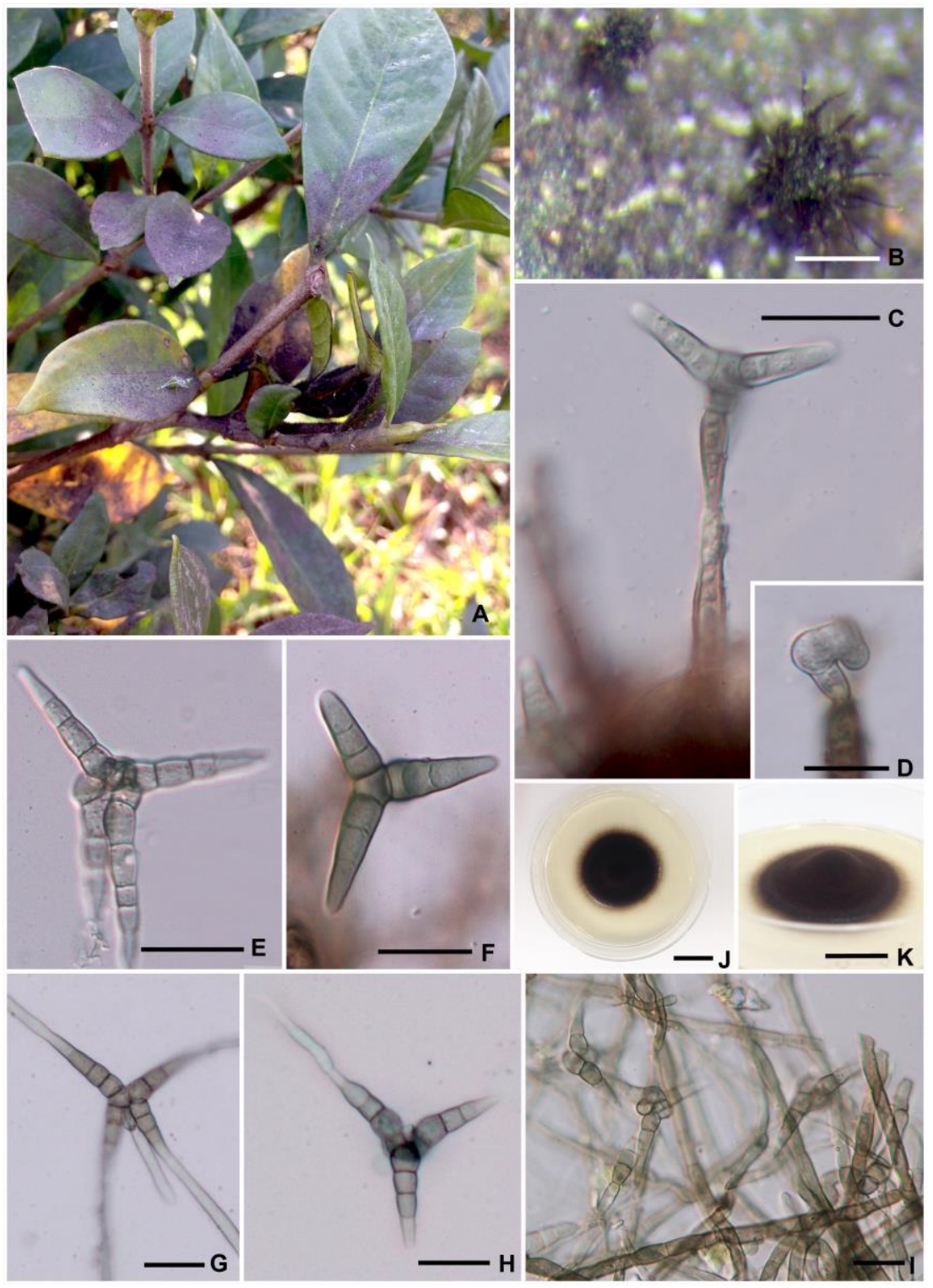

Fig. 1 - Trichomerium gloeosporum. A. Sooty molds on host. B. Ascomata of Trichomerium gloeosporum (sexual morph). C. Conidia arising from conidiophore which are reduced to conidiogenous cells. D. Immature conidia. E, F. Conidia. G, H. Conidia germinating on media. I. Conidia with septate hyphae. J, K. Colonies on media. Scale bars: C, E-I $=20 \mu \mathrm{m}, \mathrm{d}=10 \mu \mathrm{m}, \mathrm{J}, \mathrm{K}$ $=1 \mathrm{~cm}$. 
Notes: The asexual morph characters found in this study are identical to Tripospermum in having branched conidia, giving rise to 3-4 lateral arms from a central cell. The combined of LSU and ITS sequence data obtained from "Tripospermum-like" conidia indicate that our isolates are the same species as T. gloeosporum with $90 \% \mathrm{ML}$ and 1.0 PP support, even thought they were isolated from "Tripospermum-like" conidia. The sexual morph associated with Tripospermum-like conidia in our specimens is morphologically typical to $T$. gloeosporum and thus confirms the linkage.

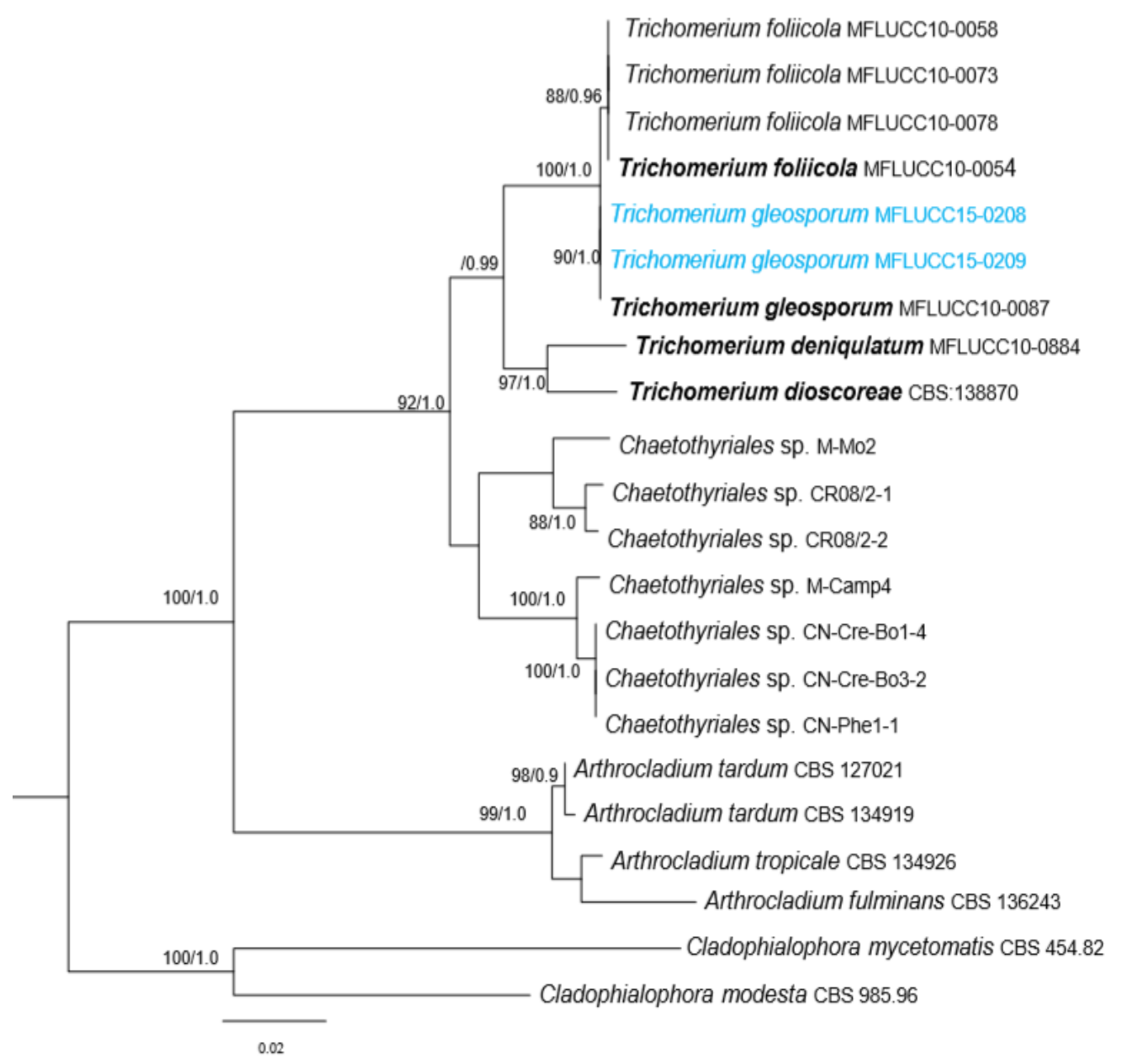

Fig. 2 - RAxML maximum likelihood phylogenetic tree based on combined LSU and ITS sequence data. The first set of numbers above the nodes are RAxML value expressed from 1,000 repetitions with values above $70 \%$ shown. The second set of numbers above the nodes are Bayesian posterior probabilities, with values above 0.95 shown. Strain numbers are indicated after species names. New sequence data are in blue bold, and other types are in black bold.

\section{Discussion}

Trichomerium is the generic type of Trichomeriaceae (Chomnunti et al. 2012a, b, 2014, Liu et al. 2015), with the type species Trichomerium coffeicola (Puttemans) Speg. Twenty-seven species epithets are listed in Index Fungorum (2016). Molecular analyses indicate that species of Trichomerium cluster separately from Capnodiaceae and Chaetothyriaceae (Chomnunti et al. 2012a, b, 2014, Yang et al. 2014, and this study) and is included with three other genera in Trichomeriaceae (Nascimento et al. 2016). Trichomerium gloeosporum was introduced by Chomnunti et al. (2012a) based on phylogenetic analyses and the distinct morphology of the sexual morph. Crous et al. (2015) collected Tripospermum on leaves of Dioscorea sp. (Dioscoreaceae), and introduced a new species Trichomerium dioscoreae Crous \& C. Nakash. based on phylogenetic analyses of LSU and SSU sequence data using a megablast search of GenBank. We collected a Tripospermum species on Gardenia sp. (MFLU 16-2885) and isolated strains from single conidia (Fig. 1). The strains produce the Tripospermum asexual morph in culture (Fig. 1). Our strain differs 
from $T$. dioscoreae in having 3-4 lateral arms from a central cell, with 2-5-septa, while $T$. dioscoreae has 2- lateral arms, with 1-2-septa. Ascomata were associated with the Tripospermum morph and had the same characters as Trichomerium gloeosporum. Molecular analyses based on combined data set of LSU and ITS sequence data indicate that our taxa is the same species with $T$. gloeosporum (90\% ML and 1.0 PP support; Fig. 2), which confirms this linkage. In this paper we provide the first description of the asexual morph of $T$. gloeosporum, with sequence data.

\section{Acknowledgements}

We would like to thank Mushroom Research Foundation and Center of Excellence in Fungal Research, Thailand. Dian-Ming Hu thanks the grant number NSFC 31460009 and NSFC 31500021 for funding this research.

\section{References}

Cai L, Jeewon R, Hyde KD. 2006 - Phylogenetic investigations of Sordariaceae based on multiple gene sequences and morphology. Mycological Research 110, 137-150.

Cai L, Guo XY, Hyde KD. 2008 -. Morphological and molecular characterization of a new anamorphic genus Cheirosporium, from freshwater in China. Persoonia 20, 53-58.

Chomnunti P, Bhat DJ, Jones EBG, Chukeatirote E et al. 2012a - Trichomeriaceae, a new sooty mould family of Chaetothyriales. Fungal Diversity 56, 63-76.

Chomnunti P, Ko Ko TW, Chukeatirote E, Cai L et al. 2012b - Phylogeny of Chaetothyriaceae in northern Thailand including three new species. Mycologia 104, 382-395.

Chomnunti P, Hongsanan S, Hudson BA, Tian Q et al. 2014 - The sooty moulds. Fungal Diversity $66,1-36$.

Crous PW, Wingfield MJ, Schumacher RK, Summerell BA et al. 2015 - Fungal Planet Description Sheets: 281-319. Persoonia 33, 212-289.

Egenlauf B, Schuhmann T, Giese T, Junghanss T et al. 2015 - Disseminierte mykose mit Arthrocladium species gefährdete patientin mit GATA-2 Defekt Pneumonologie 69. doi.org/10.1055/s-0035-1544842 S 01

Hall TA. 1999 - BioEdit: a user-friendly biologica 1 sequence alignment editor and analysis program for windows 95/98/NT. Nucleic Acids Symposium Series 41, 95-98.

Hubka V, Réblová M, Rehulka J, Selbmann L et al. 2014 - Bradymyces gen. nov. (Chaetothyriales, Trichomeriaceae), a new ascomycete genus accommodating poorly differentiated melanized fungi. Antonie Van Leeuwenhoek International Journal of General and Molecular Microbiology 106, 979-992.

Huelsenbeck JP, Ronquist F. 2001 - MRBAYES: Bayesian inference of phylogenetic trees. Bioinformatics 17, 754-755.

Index Fungorum. 2016 - http://www.indexfungorum.org/Names/Names.asp.

Isola D, Zucconi L, Onofri S, Santamaria U et al. 2016 - Extremotolerant rock-inhabiting black fungi from Italian monumental sites. Fungal Diversity 76, 75-96.

Jayasiri SC, Hyde KD, Ariyawansa HA, Bhat JD et al. 2015 - The Faces of Fungi database: fungal names linked with morphology, phylogeny and human impacts. Fungal Diversity 74, 3-18

Katoh K, Asimenos G, Toh H. 2009 - Multiple alignment of DNA sequences with MAFFT. Methods in Molecular Biology 537, 39-64.

Liu JK, Hyde KD, Jones EBG, Ariyawansa HA et al. 2015 - Fungal diversity notes 1-110: taxonomic and phylogenetic contributions to fungal species. Fungal Diversity 72, 1-197.

Nascimento MMF, Selbmannc L, Sharifyniab S, Al-Hatmib AMS et al. 2016 - Arthrocladium, an unexpected human opportunist in Trichomeriaceae (Chaetothyriales). Fungal Biology 120, 207-218.

Nylander JAA, Wilgenbusch JC, Warren DL, Swofford DL. 2008 - AWTY (are we there yet?): a system for graphical exploration of MCMC convergence in Bayesian phylogenetics. Bioinformatics 24, 581-583. 
Rannala B, Yang Z. 1996 - Probability distribution of molecular evolutionary trees: a new method of phylogenetic inference. Journal of Molecular Evolution 43, 304-311.

Réblová M, Untereiner WA, Réblová K. 2013 - Novel evolutionary lineages revealed in the Chaetothyriales (Fungi) based on multigene phylogenetic analyses and comparison of ITS secondary structure. PLoS ONE 8, e63547.

Spegazzini C. 1918 - Notas micológicas. Physis Revista de la Sociedad Argentina de Ciencias Naturales 4, 281-295.

Silvestro D, Michalak I. 2012 - RaxmlGUI: a graphical front-end for RAxML. Organisms Diversity \& Evolution 12, 335-337.

Tsuneda A, Hambleton S, Currah RS. 2011 - The anamorph genus Knufia and its phylogenetically allied species in Coniosporium, Sarcinomyces, and Phaeococcomyces. Botany 89, 523-536.

White TJ, Bruns T, Lee S, Taylor J. 1990 - Amplification and direct sequencing of fungal ribosomal RNA genes for phylogenetics. In: PCR Protocols: a guide to methods and applications. (Innis MA, Gelfand DH, Sninsky JJ, White TJ, eds). Academic Press, New York, USA, 315-322.

Yang H, Chomnunti P, Ariyawansa H, Wu HX, Hyde KD. 2014 - The genus Phaeosaccardinula (Chaetothyriales) from Yunnan, China, introducing two new species. Chiang Mai Journal of Science 41, 873-884.

Zhaxybayeva O, Gogarten JP. 2002 - Bootstrap, Bayesian probability and maximum likelihood mapping: exploring new tools for comparative genome analyses. BMC Genomics 3, 4. 